\title{
Patients' Perception and Satisfaction on Model Pharmacies in Dhaka City, Bangladesh
}

\author{
Jesmin Sultana \\ Department of Business Administration, University of Asia Pacific, Dhaka, Bangladesh \\ (Received: October 25, 2017; Accepted: December 20, 2017; Published: January 30, 2018)

\begin{abstract}
The aim of the present study is to find out the patients' perception and satisfaction about model pharmacies in Dhaka city, Bangladesh. Model pharmacies of Dhanmondi, Mohammadpur, Mirpur, Kalabagan, Green road, Panthopath, Mohakhali, Gulshan and old Dhaka were considered as the study area. The factors for better health care service have been discussed from the points of patients' perception. Pharmaceutical sector of Bangladesh is improving day by day although the inclusion of graduate pharmacists in the health sector is not yet implemented. Lack of modern facilities, improper management of medicines, selling of poor quality medicines as well as no counseling in pharmacies for the patients by "A grade" pharmacists are major causes of poor quality health care service. Recent initiation of model pharmacies in Bangladesh may be a hope for better healthcare management and patients' satisfaction. The correlation matrix shows the factors that impact patients' satisfaction and purchasing decision in model pharmacy. The most important and significant factors are counseling by "A grade" pharmacists, patient database system, affordable price and quality of medicines. Recommendations have been made for further improvement of the model pharmacies from the patients' point of view and satisfaction, which might help to create a model for other developed and developing countries.
\end{abstract}

Key words: Model pharmacy, A grade pharmacist, better health care, patients.

\section{Introduction}

Pharmaceutical sectors of Bangladesh are one of the promising sectors of the country (Sultana, 2016). Although the health sector is not fully developed because of improper management of drugs, selling of adulterated and substandard drugs as well as the lack of patients counseling ( Elias et al., 2016). Retail pharmacies are the market place where the patients purchase medicines when they are required and where they are wanted (Chagati, 2005). Retail pharmacies act as a bridge among the patients, pharmaceutical manufacturers and physicians. In Bangladesh, private or retail pharmacies are the most convenient 'first point of call' for advice on common health related problems (Ahmed et al. 2009). Being a lower middle income countries and shortage of physicians, the retailers of these pharmacies play important roles in promoting access to medicines (Wafula et al. 2012). The retail pharmacists should have qualification and license to sell pharmaceutical preparation. Patient compliance is hindered in Bangladesh as these retailers are mainly "C grade" pharmacists, who only take a short training of 12 weeks and lack of knowledge in patient counseling. Based on these problems, the government of Bangladesh promulgated The National Drug Policy in 2016 to ensure rational and safe use of quality drugs with proper dispensing and affordable price. The idea of model pharmacy has been generated after this policy from Tanzania based "Accredited Drug Dispensing Outlet" model which is also known as ADDO model. Before 2003, Duka La Dawabaridi (DLDB) was the largest licensed outlets for essential medicines in Tanzania. But after an

Correspondence to: Jesmin Sultana; Tel: +880-2-58157091, Fax: +880-258157097; E-mail: jesmin@uap-bd.edu 
assessment in 2001, it was found that, DLDB has certain short comings like medicine quality, inadequate storage of medicines, untrained staff, inadequate supervision and enforcement, authorization to sell only a limited OTC medicines and illegal dispensing of prescription medicines. To solve these problems, Management Sciences for Health's Strategies for enhancing access to medicines program began working with the government of Tanzania and ensure the affordable, quality medicines and pharmaceutical services. This is similar to the situation of Bangladesh. In 2016, an accreditation program was established to make the retail pharmacies of Bangladesh a safe guard and standardized one to render good public healthcare. DGDA published the standards for accreditation of retail pharmacies with the technical support from Management Sciences for Health (MSH) with Department for International Development (DFID) funding through Joint Donor Technical Assistance Fund (JDTAF). These accredited shops are designated as "Model" outlets when it meets the predetermined standards. These models have been categorized into two categories which are level 1 and level 2. Model pharmacies are in level 1 group. In level 2, model medicine shops are included. Model pharmacy which is in level 1 should be managed and supervised by an "A grade" pharmacist. "B and C" grade pharmacists may help or assist with dispensing under the supervision of "A grade" pharmacist. As pilot project, it was decided to establish thirty level 1 pharmacies in Dhaka, Rajshahi, Khulna, Barisal and Sylhet divisional headquarters and Gazipur district town. According to the DGDA the current number of model pharmacies in Bangladesh is 185. The standards that the model pharmacies need to follow include:

Standards for personnel: Owner with proper license and "A grade" pharmacist having registration from the Pharmacy Council of Bangladesh will be able to run a model pharmacy. Under the supervision of "A grade" pharmacists, "B and C" grade pharmacists will provide service in model pharmacy. There will be contract between model pharmacy owner and pharmacists in charge as per the Pharmacy
Council Guideline. Lacking of manpower hampers the proper functioning of the model pharmacies. This is why adequate man power is very much needed (Alomi, 2016).

Standards for location and premises: It is hard to find the exact location of the model pharmacies in an area. Again it is not sure either all the medicines will be available or not. Medicine Procurement from Data Base System (MPDS) can be introduced. Through MPDS, it is possible to find out the exact location of the pharmacies in an area and the required medicines with price and assured online delivery (Saha, 2017). Appropriate location is very important where patients can go easily. Premises should have good layout, convenient to move and have temperature control system, refrigerator and professional service area and security system.

Modern facilities: Proper knowledge and training along with modern facilities all are the main back bones of dispensing and management of medicines (Sahaet, 2017). Good Dispensing Practices, Counseling Patients, Dispensing Containers, Required Dispensing Tools, Labeling Dispensed Medicines, Storage of Medicines, Hygienic environment, Disposal of Damaged/Expired Medicines, Allowable Products and Services in Model Pharmacies, Prescription-only Medicines, Non-prescription/Over-the-Counter (OTC) Medicines, Medical Supplies and Devices, Nonpharmaceutical products and Provision of other Health Services are equally important. Packaging should be done carefully and guidance should be given to the patients so that wrong medicines are not taken by the patients (Rahman and Parvin, 2015).

Computerized data based system: Computerized Data Base System should be used for convenient use of inventory management. Digital records of the patients and medicines are to be maintained rather than noting few information only (Elias et al., 2016). Record keeping of sale and inventory control for maintaining stocks and patients records are very important for running pharmacy smoothly to satisfy the needs of the patients. 
Reasonable pricing of pharmaceuticals: The price of medicines is very important factor that influence patient to purchase medicines. Most of the patients of Bangladesh belong to lower middle income group. They face problem to spend their hard earning money for treatment. Most of the time they cannot continue the treatment (Kabir 2010). New drug policy 2016 has taken initiative to monitor and control the high price of medicines through model pharmacy.

Quality medicines from reputed pharmaceutical companies: Efficacy of any medicine depends on specific standard formulation. It needs to be formulated according to BDNF or USP/BP maintaining good manufacturing practice (GMP). So the pharmaceutical companies producing medicines for healthcare of the patients should be authorized by the approval of the government authority like DGDA. In order to reduce adulterated medicines in the market and ensure quality medicines to the patients, model pharmacies should collect medicines only from DGDA approved pharmaceutical companies. Storage condition and facility play the most vital role in pharmacy and quality of medicines depend on the storage condition (British Pharmacopeia, 2009).

Thus, the main objectives of the study are to analyze patient's satisfaction level about the recent concept of Model Pharmacies in Dhaka city and identify the factors or attribute that influence patients to purchase medicines from the Model Pharmacies rather than conventional retail drug stores.

\section{Research Methods}

This research was carried out both qualitatively and quantitatively to explore the impact of model pharmacy concept on buying decision of the customers (patients). The primary research was performed by development of structured questionnaire which include demographic information of respondents and 5 point Likert scale having different factors that represent the satisfaction level of patient to select model pharmacy instead of retail pharmacy. Research questions were asked to know how the patient's purchasing decisions are being influenced by concept of Model Pharmacy, what are the important factors of Model Pharmacies that impact on patient's satisfaction to buy medicines etc.

Secondary information was collected from reputed national and international journals, books, websites, articles etc. Some information were also collected from discussion with the "A grade" pharmacists of model pharmacies and legal bodies of model pharmacies.

In this research, the customers (patients) of model pharmaciesin different areas such as Dhanmondi, Mohammadpur, Mirpur, College gate, Green road, Panthopath, Kollabagan, Mohakhali, Gulshan and Old Dkaka have been selected by convenient sampling technique. The sample size was limited to 100 .

\section{Results and Discussion}

Location and premises: The respondents were asked about the location of model pharmacies and how they came to know about it. $42 \%$ of them expressed their satisfaction and $50 \%$ were found to be very satisfied. They answered that they came to know the location while walking, doctors' recommendation, face book and newspapers.

Quality of medicines: Quality of medicines is very important to cure the health related problems and to ensure safety to the patients. The patients who purchase medicines from model pharmacies rather than conventional pharmacies responded that $45 \%$ are satisfied and 53\% are very satisfied about the quality of the medicines and services rendered by the former one (Figure 1). Quality of medicine has an impact on patients' satisfaction and is the second important variable having significant value 0.023 which is below 0.05 (Table 4).

Modern facilities: Model pharmacies are designed and organized in such a way that show the good dispensing practice, hygienic environment and display OTC and prescription medicines in separate places. Storage condition of the medicines at suitable temperature and provision of medical devices and healthcare services were noticed. $60 \%$ of the patients responded their satisfaction in positive way and $29 \%$ were found very satisfied (Figure 1). 


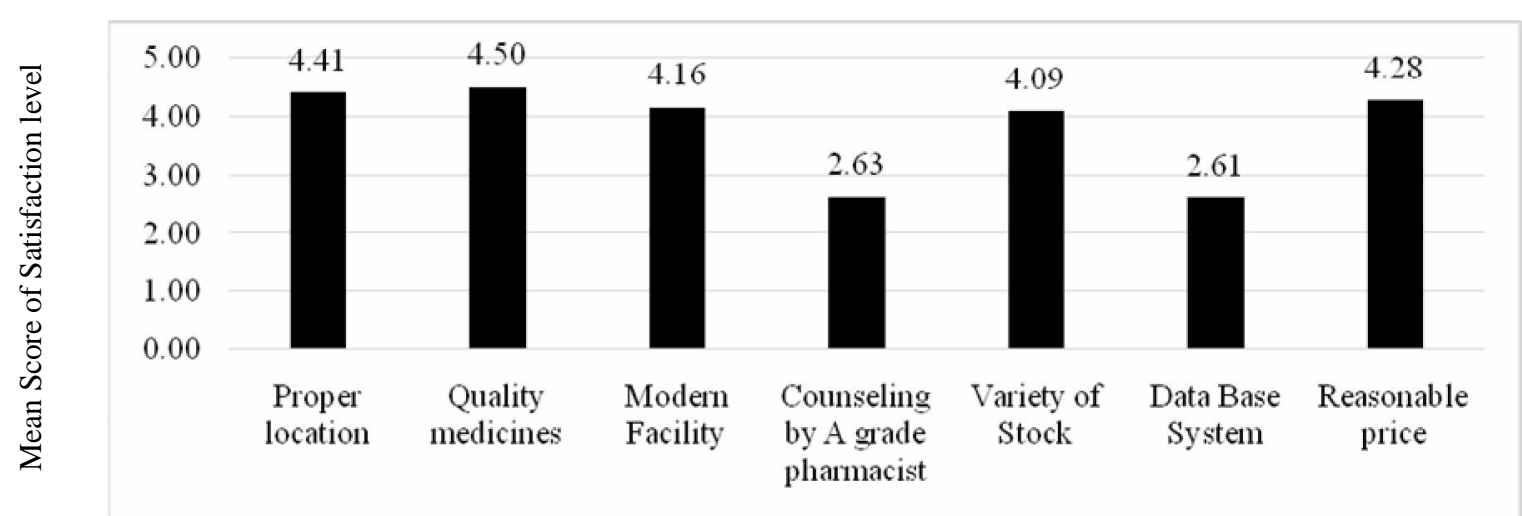

Figure 1. Patients' perception and satisfaction of seven factors about Model pharmacies in Dhaka city.

Counseling by "A grade" pharmacists: Pharmacists are the expert in pharmaceutical preparations, especially medicines. Role of "A grade" pharmacists are to advise patients about the medicines, doses and frequencies of uses, indications, contraindication, side effects etc. New Drug Policy has taken initiative to introduce "A grade" pharmacists for counseling patients and "B and C" grades will assist the "A grade" pharmacists for selling medicines. The survey showed that the patients are not aware about the role of "A grade" pharmacists and most of the time pharmacists were not available in their desks. Out of 20 model pharmacies, only 7 "A grade" pharmacists were found during visit by the patients. $65 \%$ of the patients replied that they were not satisfied and $31 \%$ of them were satisfied (Figure 1). In order to determine the most crucial factor that impacts on patients' satisfaction to purchase medicines from model pharmacies is counseling by "A grade" pharmacists, as the significance level is about 0.000 (table 4).

Variety of stocks: Physicians prescribe different medicines and the patients expect that they will get all medicines from one pharmacy rather than to look for them in other pharmacies. Model pharmacy should have collection of all type of medicines according to prescription survey and type of diseases that occur most. About $88 \%$ of the respondent expressed their satisfaction about the variety of stocks in model pharmacy while $6 \%$ were not satisfied (Figure 1).
Computerized data base system: Computerized data base system to record inventory and patient's transaction of medicines are very important for better management and on-time delivery of medicines to the patients to maintain good relation and repeat business. The records of the patients and on-line service need to be introduced. The patients were asked about this service, $65 \%$ responded negatively and $22 \%$ were found to be satisfied. Correlation matrix shows the impact of computerized data base system on patients' satisfaction as the second most important factors which has a value of 0.590 (Table 1).

Reasonable price: Price of the medicines is very important factor to the patients for their healthcare and continued treatment. Most of the patients were found to be service holder during the survey and cannot afford high price. The respondents (95\%) expressed their satisfaction about the reasonable price of the medicines.

Table 3 states that calculated value of $F$ is 29.299 which indicates that the variables have impact on patients' satisfaction to purchase from model pharmacy.

Correlation analysis: Correlation Matrix showed inter correlation among the seven factors or independent variables such as proper location, quality medicines, modern facility, counseling by "A grade" pharmacist, variety of stock, data base system and reasonable price with dependent variable Patients' satisfaction on model pharmacy (Table 1). 
Table 1. Correlation matrix of model pharmacy factors and overall satisfaction $(n=100)$.

\begin{tabular}{|c|c|c|c|c|c|c|c|c|}
\hline & $\begin{array}{l}\text { Proper } \\
\text { location }\end{array}$ & $\begin{array}{l}\text { Quality } \\
\text { medicines }\end{array}$ & $\begin{array}{l}\text { Modern } \\
\text { Facility }\end{array}$ & $\begin{array}{l}\text { Counseling } \\
\text { by A grade } \\
\text { pharmacist }\end{array}$ & $\begin{array}{l}\text { Variety } \\
\text { of Stock }\end{array}$ & $\begin{array}{l}\text { Data } \\
\text { Base } \\
\text { System }\end{array}$ & $\begin{array}{l}\text { Reasonable } \\
\text { price }\end{array}$ & $\begin{array}{l}\text { Overall } \\
\text { satisfaction }\end{array}$ \\
\hline $\begin{array}{l}\text { Proper } \\
\text { location }\end{array}$ & 1 & $0.275 * *$ & 0.147 & 0.034 & $0.273^{* *} *$ & -0.044 & 0.035 & 0.036 \\
\hline $\begin{array}{l}\text { Quality } \\
\text { medicines }\end{array}$ & $0.275^{* *}$ & 1 & $0.449 * *$ & $0.438 * *$ & $0.497 * *$ & $0.327 * *$ & $0.295^{* *}$ & $0.463 * *$ \\
\hline $\begin{array}{l}\text { Modern } \\
\text { facility }\end{array}$ & 0.147 & $0.449 * *$ & 1 & $0.246^{*}$ & $0.396^{* *}$ & $0.208^{*}$ & 0.129 & $0.283^{* *}$ \\
\hline $\begin{array}{l}\text { Counseling } \\
\text { by A grade } \\
\text { pharmacist }\end{array}$ & 0.034 & $0.438 * *$ & $0.246^{*}$ & 1 & $0.317 * *$ & $0.666^{* *}$ & $0.517 * *$ & $0.685^{* *}$ \\
\hline $\begin{array}{l}\text { Variety of } \\
\text { stock }\end{array}$ & $0.273^{* *}$ & $0.497 * *$ & $0.396 * *$ & $0.317 * *$ & 1 & $0.251 *$ & $0.341 * *$ & $0.363^{* *}$ \\
\hline $\begin{array}{l}\text { Data Base } \\
\text { system }\end{array}$ & -0.044 & $0.327 * *$ & $0.208^{*}$ & $0.666^{* *}$ & $0.251^{*}$ & 1 & $0.399 * *$ & $0.590 * *$ \\
\hline $\begin{array}{l}\text { Reasonable } \\
\text { price }\end{array}$ & 0.035 & $0.295^{* *}$ & 0.129 & $0.517 * *$ & $0.341 * *$ & $0.399 * *$ & 1 & $0.503 * *$ \\
\hline $\begin{array}{l}\text { Overall } \\
\text { satisfaction }\end{array}$ & 0.036 & $0.463 * *$ & $0.283^{* *}$ & $0.685^{* *}$ & $0.363^{* *}$ & $0.590 * *$ & $0.503 * *$ & 1 \\
\hline
\end{tabular}

Table 2. Model Summary ${ }^{\mathrm{e}}$.

\begin{tabular}{|c|c|c|c|c|}
\hline Model & $\mathrm{R}$ & R Square & Adjusted R Square & $\begin{array}{l}\text { Std. Error of the } \\
\text { Estimate }\end{array}$ \\
\hline 4 & $0.743^{\mathrm{d}}$ & 0.552 & 0.533 & 0.46479 \\
\hline
\end{tabular}

Table 3. ANOVA ${ }^{\mathrm{a}}$.

\begin{tabular}{llccccc}
\hline Model & & Sum of squares & df & Mean Square & F & Sig. \\
\hline \multirow{4}{*}{4} & Total & 45.840 & 99 & & & $0.000^{\mathrm{e}}$ \\
& Regression & 25.317 & 4 & 6.329 & 29.299 & \\
& Residual & 20.523 & 95 & 0.216 & & \\
\hline
\end{tabular}

a. Dependent Variable: Overall satisfaction

e. Predictors: (Constant), Counseling by “A grade” pharmacist, Quality medicines, Data Base System, Reasonable price

The overall model was found to be significant, $\mathrm{F}=29.299$ with $\mathrm{p}=0.000<0.05$ (Table 3). 
Table 4. Coefficients ${ }^{\mathrm{a}}$.

\begin{tabular}{|c|c|c|c|c|c|c|}
\hline \multicolumn{2}{|c|}{ Model } & \multicolumn{2}{|c|}{ Unstandardized Coefficients } & \multirow{2}{*}{$\begin{array}{l}\text { Standardized } \\
\text { coefficients } \\
\text { Beta }\end{array}$} & \multirow[t]{2}{*}{$\mathrm{t}$} & \multirow[t]{2}{*}{ Sig. } \\
\hline & & B & Std. Error & & & \\
\hline \multirow[t]{5}{*}{4} & (Constant) & 1.419 & 0.467 & & 3.041 & 0.003 \\
\hline & Counseling by "A grade" pharmacist & 0.182 & 0.049 & 0.379 & 3.697 & 0.000 \\
\hline & Quality medicines & 0.209 & 0.090 & 0.178 & 2.313 & 0.023 \\
\hline & Data Base System & 0.138 & 0.060 & 0.211 & 2.282 & 0.025 \\
\hline & Reasonable price & 0.178 & 0.084 & 0.171 & 2.113 & 0.037 \\
\hline
\end{tabular}

a. Dependent Variable: Overall satisfaction

Table 1 exhibits that patients' satisfaction is significantly and positively correlated with the quality of medicines, counseling by "A grade" pharmacists, modern facility, data base system and reasonable price but there were no significant correlation with proper location.

\section{Regression analysis}

The objective of the study was to examine the patients' satisfaction on model pharmacy in Dhaka city. Seven independent variables were measured to observe the impact on patients' satisfaction which is considered as dependent variable.

The result of the correlation matrix shows that all factors except "Proper location" are significantly correlated to the overall satisfaction. However, to identify the most important factors which have practical significance or influence on overall satisfaction, step-wise multiple linear regression has been applied. The SPSS output of final result of stepwise regression is shown below. Table 2 shows that $\mathrm{R}$ square $=0.552$. It indicates that the fitted model can explain $55.2 \%$ variation of dependent variable (Patients' Satisfaction).

Although the overall model is significant, counseling by "A grade" pharmacist, Quality medicines, Data Base System and reasonable price was found highly significant and positively correlated that influence patients' satisfaction to select model pharmacies rather than conventional retail pharmacies (Table 4). Variety of stocks, modern facility and proper location was found to be not significant.

\section{Estimated Regression Equation:}

$\hat{\gamma}=1.419+0.209 * F 2+0.182 * F 4+0.138 * F 6+0.178 * F 7$

Where, $\mathrm{Y}=$ Overall satisfaction, $\mathrm{F} 1=$ Proper location, $\mathrm{F} 2=$ Quality medicines, F3=Modern Facility,F4 = Counseling by A grade pharmacist, F5 = Variety of Stock, F6=Data Base System, F7 = Reasonable Price, F8 = Overall Satisfaction

Demographic Profile of the Patients includes gender, age and occupation. In this study majority of the respondents are male and the percent is $69 \%$. The percent of the female was $31 \%$. The respondents involved in the survey are of the age 20-29 years (30\%), 30-39 years (33\%), 40-49 years (15\%) and 50 years and above (23\%). The occupation of the respondents were as follows - $48 \%$ service holders, $15 \%$ businessmen, $8 \%$ housewives and $17 \%$ belonged to other profession (e.g driver, caretakers, retired people, rickshaw pullers).

\section{Recommendations}

In Bangladesh patients suffer a lot because of improper patient counseling and management of drugs. Drug storage condition is not well developed here which causes the deterioration of drugs as well as the medical devices. On the other hand, digitalized system is not well adapted. Model pharmacy may be a suitable method to fight this situation. However, many facilities should be adapted and laws should be enforced for better patient care and management. After surveying and analyzing the data, the following 
suggestion can be taken under consideration to establish a better model pharmacy for improved patient care and management. Some recommendations may be as follows:

- Model pharmacies should provide patients with sufficient seats in case of a queue. They should also contain wash room facilities. Journals, books and leaflet having medical awareness be stored for spreading the knowledge to the patients.

- Counseling by "A grade" pharmacist should be done in separate room in contrast to the prevailing open-space. The patients are also not aware about the role of the pharmacists. This point should be taken under consideration.

- Model pharmacy should be run by adequate number of "A grade" and "C grade" pharmacists. "B grade" pharmacist may also be employed. Lacking of manpower hampers proper functioning of the pharmacy.

- Model pharmacies should maintain the proper temperature for storing drugs and medicines.

- LASA products (Similar name and similar looking products) should be stored under the tall man lettering procedure.

- Supply and availability of medicines in model pharmacy should be ensured from authentic sources. It should be verified that, the companies are government authorized or not. Medicines should be procured from the top ranking pharmaceuticals which have reputation. Requisition of drugs should be sent to the supplier before they are short in the inventory. Lifesaving and fast moving drugs should be available in the model pharmacy all the time.

- Inventory should be kept and it may be computerized for convenient use. System analyses and data processing (SAP) can be used. Digitalized inventory is more convenient than the manual one.

- Digital record keeping of patients and drugs should be kept. It's better to keep all the information rather than few information in a digitalized system for trend analysis and discount for patients.

- Adverse drug reactions (ADRs) form is very much needed for patient safety. If any ADRs are found that should be immediately send to the authority for checking. It will enrich the health sectors and patient's safety will be ensured.

- In developed countries online drug delivery system is very much popular and it is convenient to the patient. Model pharmacies can introduce online drug delivery system for patient's compliance.

- Medicine procurement from database system (MPDS) can be introduced. Through MPDS, it is possible to find out the exact location of pharmacies in an area and the required medicines with costs. Online drug delivery system can be introduced for patients' satisfaction.

- "A grade" registered pharmacist should be available all the time. It is one the most important factor which makes the model pharmacies superior to the retail pharmacies. Authority should pay attention to this issue.

- Remunerations of pharmacists should be paid between times and monitored by the government. The registration and renewal of the registration should be done timely. On the other hand, "A grade" pharmacist works during the weekday so patients suffer during weekends. More than one pharmacist should be employed and roaster system can be applied for 24 hours.

- To create awareness about the role of the pharmacists among the patients so they can understand the importance of suggestions of "A grade" pharmacists, advertisement in newspapers, social media and conducting campaign about the importance of "A grade" pharmacists' role in healthcare are very important.

- Role of pharmacists in checking the prescription and suggestion over prescription should be considered carefully to see if any irrational medicines have been prescribed. 
- Some pharmacies remain open for 24 hours and some for 8 to 20 hours. By introducing roaster system of the employee, it is possible to have 24 hours open model pharmacy which will be more patient friendly.

- Stocks of highly demanding OTC and prescription medicines should be available in the model pharmacy to get competitive advantages and patients' satisfaction.

- Model pharmacies may have the facilities of rendering services related to medical equipment's and tests like diabetes, blood pressure measurement etc. In these ways, the model pharmacies can be popular and the people will go and buy medicines from safer source. But it should be kept in mind that patient get these benefits in proper ways and not for just business purpose. These should be handled by trained personnel.

- A lot of the model pharmacies do not store narcotic drugs and have narcotic license. But drug administration may encourage the owner to get a license and store and sell because the regulations of narcotic drugs can be ensured properly.

\section{Conclusions}

Model pharmacy may be a suitable method to solve the health care related problems of Bangladesh. It is possible to ensure patients' safety and satisfaction by the expansion of model pharmacy and fulfilling the requirement of the criteria that influence patients to purchase medicines from model pharmacies rather than conventional retail pharmacies. The sale of adulterated drugs and misuse of drugs can be reduced. Adaption of newer technologies and facilities can make this system more convenient to the patients. Legal authority should aware people about model pharmacies as it is very much new in Bangladesh. Government and legal bodies should pay special attention so that model pharmacy can run smoothly according to the Drug
Policy 2016. From the research it has been found that importance of counseling by "A grade" pharmacists is to be spread for rational use of medicines. Counseling by "A grade" pharmacists, patient's data base system, reasonable price and quality of medicine should be ensured to attract patients for their satisfaction and positive perception to purchase medicines only from the model pharmacies.

\section{References}

Ahmed, S.M., Hossain, M.A. and Chowdhury, M.R. 2009. Informal sector providers in Bangladesh: how equipped are they to provide rational health care? Health Policy and Planning. 24, 467-78.

Alomi, Y.A. 2016. A New Guidelines on Hospital Pharmacy manpower in Saudi Arabia. J. Pharm. Pract. Community Med. 2, 30-31.

British pharmacopoeia. 2009. 1141-1149.

Chaganti, S.R. 2005. Pharmaceutical Markeing in India, 175-178.

Elias-Al-Mamun, Saha,T. and Islam, M.R. 2016. Initiation and Maintenance of Diseases and Diagnostic Databases of Bangladeshi Individual. American $J$. Pharm. Health Res. 4, 30-42.

Kabir R.E. 2010. A strategic analysis of the Pharmaceutical sector of Bangladesh. PhD Thesis.

Rahman, Z. and Parvin, R. 2015. Medication errors associated with look-a-like/sound-a-like drugs: A brief review. J. Enam. Med. Col. 5, 110-117.

Saha, T. 2017. Medicines Procurement System from Database System (MPDS) for Bangladeshi Individual: A Proposal. Der. Pharmacia. Sinica. 8, 9-12.

Saha, T., Bhuiyan, R.H., Masum, Z.U., Islam, M.R. and Chowdhury, J.A. 2017. Hospital Pharmacy Management System and Future Development Approaches in Bangladeshi Hospital. Bangladesh Pharm. J. 20, 181-188.

Sultana, J. 2016. Future Prospects and Barriers of Pharmaceutical Industries in Bangladesh. Bangladesh Pharm. J. 19, 53-57.

Wafula, F.N., Miriti, E.M. and Goodman, C.A. 2012. Examining characteristics, knowledge and regulatory practices of specialized drug shops in Sub-Saharan Africa: a systematic review of the literature. $B M C$ Health Serv. Res. 12, 223.

Woods, D.J. 1997. Extemporaneous formulations problems and solutions. Pediatric Perinatal Drug. Ther. 1, 25-29. 